\section{A) Check for updates}

Cite this: Nanoscale, 2020, 12, 15137

\title{
Boosting perovskite nanomorphology and charge transport properties via a functional $D-\pi-A$ organic layer at the absorber/hole transporter interface $\uparrow$
}

\author{
Mohamed M. Elsenety, (DDa Anastasios Stergiou, (D) ${ }^{b}$ Labrini Sygellou, (D) c \\ Nikos Tagmatarchis, (iD ${ }^{b}$ Nikolaos Balis (iD ${ }^{a}$ and Polycarpos Falaras (iD) *a $^{a}$
}

The photovoltaic efficiency and stability challenges encountered in perovskite solar cells (PSCs) were addressed by an innovative interface engineering approach involving the utilization of the organic chromophore (E)-3-(5-(4-(bis(2',4'-dibutoxy-[1,1'-biphenyl]-4-yl)amino)phenyl)thiophen-2-yl)-2-cyanoacrylic acid (D35) as an interlayer between the perovskite absorber and the hole transporter (HTM) of mesoporous PSCs. The organic $D-\pi-A$ interlayer primarily improves the perovskite's crystallinity and creates a smoother perovskite/HTM interface, while reducing the grain boundary defects and inducing an energy level alignment with the adjacent layers. Champion power conversion efficiencies (PCE) as high as $18.5 \%$ were obtained, clearly outperforming the reference devices. Interestingly, the D35-based solar cells present superior stability since they preserved $83 \%$ of their initial efficiency after 37 days of storage under dark and open circuit (OC) conditions. The obtained results consolidate the multifunctional role of organic $D-\pi-A$ molecules as perovskite interface modifiers towards performance enhancement and scale-up fabrication of robust PSCs.

Received 31st March 2020

Accepted 16th June 2020

DOI: $10.1039 / \mathrm{d} 0 \mathrm{nr} 02562 \mathrm{c}$

rsc.li/nanoscale cedures occurring during perovskite formation and PSC operation is still lagging. Poor stability of the absorber is an additional issue, often related to the existence of ionic defects, ${ }^{18,19}$ such as undercoordinated lead cations, ${ }^{20}$ which are present at the grain boundaries ${ }^{21}$ of the perovskite film surface and can act as charge recombination and moisture/ oxygen penetration sites. This happens because most of the solution-processed devices are fabricated using polycrystalline perovskite thin films treated under low-temperature conditions. This creates dense defect traps $\left(\approx 10^{16} \mathrm{~cm}^{-3}\right)$ at the grain boundaries and the film surface of polycrystalline perovskites, several orders of magnitude higher than single crystals. ${ }^{22}$ Therefore, fine-tuning and full control of the crystal growth procedure are necessary, especially for large-scale implementation of highly efficient and robust devices.

In this context, organic molecules with carbonyl or other active groups ${ }^{23,24}$ have drawn attention for the effective modification of the perovskite absorbers due to their facile processability and appropriate electronic properties. Feng et al. ${ }^{25}$ proposed the utilization of an Eu-porphyrin complex creating 2D perovskite platelets within the grain boundaries, while Zhao et al. $^{26}$ incorporated a near IR organic molecule to modulate the photoresponse of the device. Additional approaches include the insertion of organic molecules with rich carboxyl groups towards efficient passivation, ${ }^{27,28}$ or the use of different 
functional compounds offering a multi-passivation effect ${ }^{29}$ while other efforts focused on the synergistic effect of metallated porphyrins ${ }^{30}$ and phthalocyanines ${ }^{31,32}$ in the operation of PSCs.

Herein, we introduced a donor- $\pi$-acceptor $(D-\pi-A)^{12}$ organic compound as an efficient interlayer that successfully passivates the surface trap states of a triple-cation perovskite layer while simultaneously acts as an effective charge carrier transporting the interlayer between the perovskite absorber and 2,2',7,7'-tetrakis[ $N, N$-di(4-methoxyphenyl)amino]-9,9'-spirobifluorene (Spiro-MeOTAD), HTM. In general, donor- $\pi$-acceptor compounds possess intramolecular charge transfer (ICT) properties. $^{33}$ Moreover, the passivation effect is supposed to increase with the polarity of the $\mathrm{D}-\pi$-A molecule. So, a strong electron-donating unit on the donor part would increase the electron density on the acceptor group and make it much more electron-rich. ${ }^{34}$ Such dipolar electron density distribution delivers improved conditions for coordination with the under-coordinated $\mathrm{Pb}^{2+}$ defects. This is the case for the D35 D- $\pi$-A compound, ${ }^{12}$ bearing a strong electron-donating amino center and a cyano group with extremely high electron attracting ability. Thus, a small amount of (E)-3-(5-(4-(bis $\left(2^{\prime}, 4^{\prime}-\right.$ dibutoxy-[1,1'-biphenyl]-4-yl)amino)phenyl)thiophen-2-yl)-2cyanoacrylic acid (D35), a triphenylamine (TPA)-based D- $\pi$-A molecule, was dissolved in chlorobenzene in different concentrations and was spin coated upon (FA/MA/Cs) $\mathrm{PbI}_{3-x} \mathrm{Br}_{x}$ films. The donor, $\pi$-spacer, and acceptor parts are triphenylamine, thiophene, and cyanoacrylic acid, respectively. The multication perovskite polycrystal ((FA/MA/Cs) $\mathrm{PbI}_{3-x} \mathrm{Br}_{x}$ ) layers below the D35 interlayer showed high crystallinity and upgraded light absorbance, while the corresponding perovskite/hole transporter interface was smoothened. In addition, the energy bands of the employed materials were aligned appropriately towards the facilitation of charge carrier extraction and transfer. Moreover, the films containing the organic chromophore showed reduced trap density due to the coordination of $\mathrm{Pb}^{2+}$ with the carboxylic group of $\mathrm{D} 35$. As a result, we obtained devices with improved power conversion efficiency by $22 \%$, in comparison to the reference ones. In addition, the modified devices presented superior stability, preserving 83\% of their initial PCE after 37 days of storage under dark and ambient $(\mathrm{RH}=25 \%)$ conditions, owing to the hydrophobic nature of D35.

\section{Results and discussion}

At first, various preliminary experiments were performed in perovskite PV devices, using the dye molecule both as an additive during the perovskite film's anti-solvent treatment ${ }^{35}$ and as an individual interlayer on top of the perovskite absorber. The results in the form of power conversion efficiencies are presented in Table S1. $\dagger$ The D- $\pi$-A compound (D35) was dissolved in chlorobenzene, while different concentrations were tested before choosing the optimum one, which is $10^{-5} \mathrm{M}$. Experiments were also performed using formamidinium bromide as an extra passivation layer. ${ }^{36}$ As a result, the presence of D35 (Fig. 1a) is beneficial in every case, though the most promising results were obtained when using it as a functional layer on top of the perovskite absorber, without any further modification and with pure chlorobenzene as the antisolvent material. The details on the exact device fabrication procedure are given in the Experimental section. To optimize the deposition conditions of the D35 layer, additional experiments were performed by varying the concentration (six different values between $10^{-6} \mathrm{M}$ and $10^{-3} \mathrm{M}$ ) of D35 in chlorobenzene. The results presented in the revised Fig. $\mathrm{S} 1 \dagger$ confirm the successful optimization and directly indicate the effect of the functional $\mathrm{D}-\pi-\mathrm{A}$ organic layer on the device performance. Therefore, we obtained the highest efficiency using a D35 solution of $10^{-5} \mathrm{M}$. In this case, the roughness analysis gives an estimation of the corresponding thickness of about $5 \mathrm{~nm}$. Fig. S2† shows the absorption spectrum of D35 dissolved in chlorobenzene. D35 shows a broad absorption peak at $445 \mathrm{~nm}$ (ref. 37) attributed to the HOMO to LUMO transition, while the peak at $323 \mathrm{~nm}$ corresponds to the HOMO-1 to LUMO transition. ${ }^{38}$

It is reported ${ }^{20}$ that the carboxylate group in a D- $\pi$-A molecular structure (inset in Fig. S2 $\dagger$ ) demonstrates high electron density, which favors interaction with the under-coordinated $\mathrm{Pb}^{2+}$ cations. To visualize the electron density distribution, electrostatic potential (ESP) analysis was performed, calculated from the density functional theory (DFT) method. As shown in Fig. 1b, the electron scarce area mainly distributes around the electron-donor part, associated with the butyl chains of the triphenylamines. On the other hand, the electron-rich cyanoacrylic acid group presents a high electron density which favors the coordination with the under-coordinated $\mathrm{Pb}^{2+}$ cations, as shown in Fig. 1c. In order to clarify the interaction of the organic molecule with the $\mathrm{Pb}^{2+}$ cations, Fourier-transform infrared spectroscopy (FTIR) measurements were performed in $\mathrm{D} 35$ with and without $\mathrm{PbI}_{2}$.

Fig. 1d shows a strong quenching of the stretching vibrational mode at $1685 \mathrm{~cm}^{-1}$ of $\mathrm{C}=\mathrm{O}$ in the carboxylic group of D35, which indicates the interaction of lead and the dye through the carboxylic group. ${ }^{25}$ Moreover, the absorbance of the D35 solution was measured with and without $\mathrm{PbI}_{2}$. The UV-vis spectrum of the $\mathrm{D} 35-\mathrm{PbI}_{2}$ complex (Fig. S3†) presents a clear red shift (from $420 \mathrm{~nm}$ to $450 \mathrm{~nm}$ ) of the main absorption peak, which clearly reveals an interaction between the dye and lead cations. In conclusion, such an effect refers ${ }^{20}$ to the strong coordinated reaction of D35 with $\mathrm{Pb}^{2+}$ that affects the $\mathrm{C}=\mathrm{O}$ bond of cyanoacrylic acid, partially breaks the $\pi$-conjugated system and disturbs the intramolecular charge transfer absorption band of the D- $\pi$-A molecule. ${ }^{39}$

In Fig. 2a, the absorbance of perovskite layers with and without D35 on top, grown upon $\mathrm{FTO} / \mathrm{TiO}_{2}$ substrates, is presented. The curves showed that the presence of the organic compound increases the absorbance of (FA/MA/Cs) $\mathrm{PbI}_{3-x} \mathrm{Br}_{x}$, specifically in the region below $650 \mathrm{~nm}$. Since D35 absorbs below $510 \mathrm{~nm}$, as shown in Fig. S2, $\uparrow$ we may attribute the increase in absorption partially to the presence of D35 and pri- 
a)

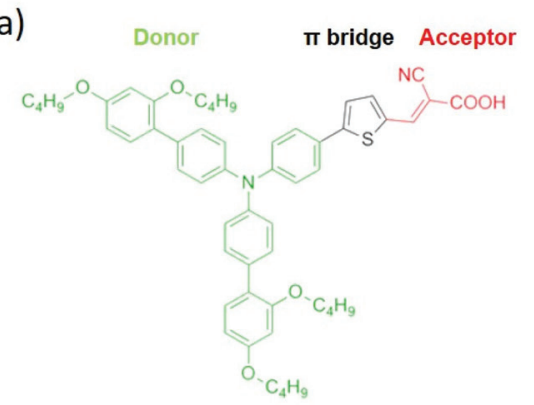

c)

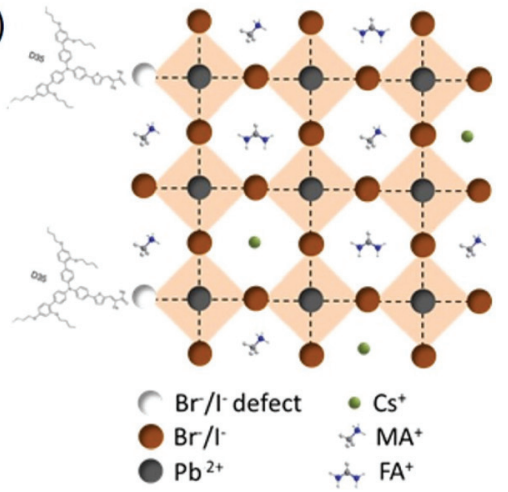

b)

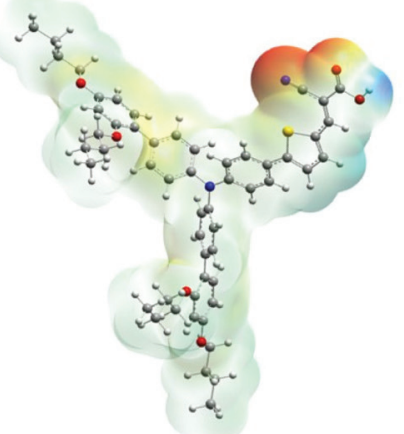

d)

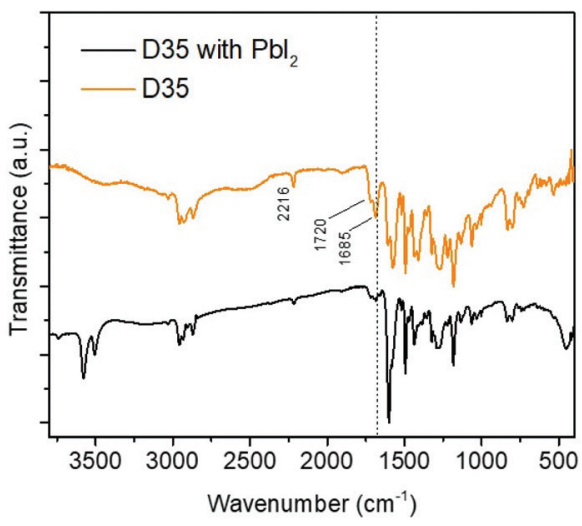

Fig. 1 Chemical structure of D35 (a); calculated ESP profiles of D35 (b); schematic illustration of the passivation process of D35 molecules for the under-coordinated $\mathrm{Pb}^{2+}$ cations (c); Fourier-transform infrared spectroscopy (FTIR) measurements in D35 with and without Pbl 2 (d).
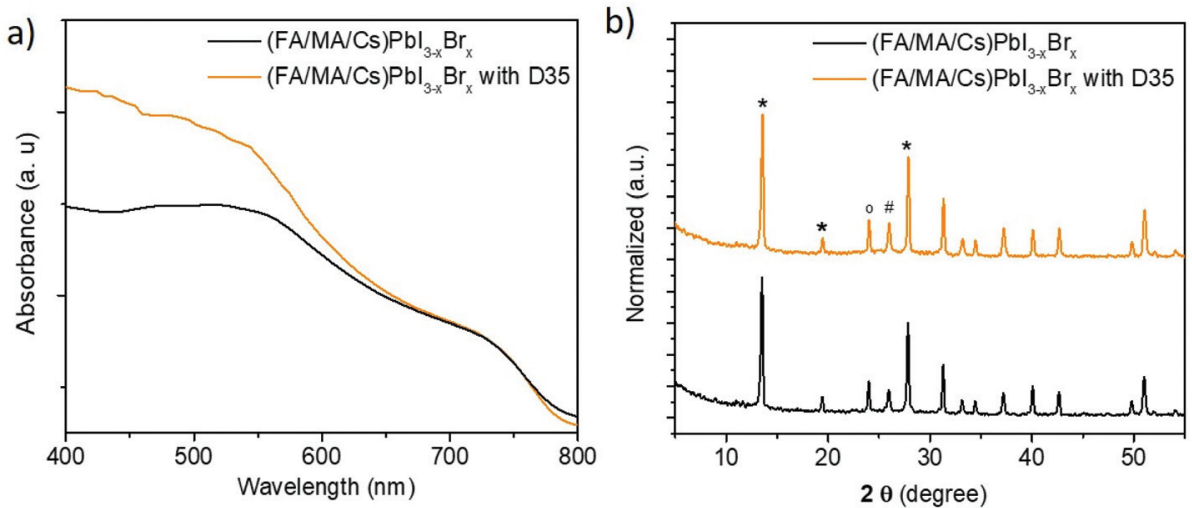

Fig. 2 UV-vis absorption spectra (a) and XRPD patterns (b) of mixed perovskite films with and without D35 treatment. Symbols "*", "o" and "\#" represent the perovskite, $\mathrm{FTO}$ and $\mathrm{TiO}_{2}$ peaks, respectively.

marily to the improved perovskite film quality, namely, compact and large perovskite grains.

The structural quality of the perovskites was examined and verified by X-ray powder diffraction (XRPD) analysis (Fig. 2b), which confirmed the presence of the main reflections from the (FA/MA/Cs) $\mathrm{PbI}_{3-x} \mathrm{Br}_{x}$ perovskite (at $2 \theta=13.5,19.4$, and $27.8^{\circ}$ ), titania (at $2 \theta=26^{\circ}$ ) and FTO (at $2 \theta=24^{\circ}$ ) layers. ${ }^{40-42}$ The trace of the two patterns is similar; however, in the presence of D35, stronger perovskite diffraction peaks are grown, a fact associated with perovskite's improved crystallinity. On the other hand, full width half maximum (FWHM) analysis showed no difference $\left(0.24^{\circ}\right.$ for the 001 peak for both samples). FWHM is associated with the size of crystallites via Scherrer's equation. However, this is a mean value estimation, thus the size will be precisely estimated by scanning electron microscopy (SEM) analysis. A more careful observation (Fig. S4†) shows that the peak position presents a slight shift (from $13.50^{\circ}$ to $13.55^{\circ}$ ) upon D35 molecule interaction. This 
shift can be associated with the relative geometrical position of the sample; however, the interaction of D35 with the perovskite lattice cannot be excluded. ${ }^{43}$ However, even in the latter case, permeation into the perovskite crystal induces neither a phase transition nor forms any 2D structures on the surface of the perovskite films. ${ }^{19}$ Moreover, Fig. S5 $\dagger$ shows the diffuse reflectance spectra transformed in Kubelka-Munk units, according to the following equation: ${ }^{11}$

$$
F(R)=\frac{(1-R)^{2}}{2 r},
$$

where $R$ is the reflectance and $h v$ is the photon energy. $[F(R) \times$ $h \nu]$ is plotted as a function of energy $(\mathrm{eV})$. By extrapolating the curves, the band gap energies have been estimated at $1.62 \mathrm{eV}$ for both D35-containing and reference samples, indicating that the optical bandgap of the mixed perovskite is not altered in the presence of the organic compound.

Afterwards, the surface of the perovskite films was examined via contact angle measurements and microscopy techniques. At first, the wettability of the chromophore interlayer was evaluated by the contact angle measurements presented in the ESI (Fig. S6 $\dagger$ ). As shown, in the presence of D35, the contact angle increases from $62.63^{\circ}$ for the reference to $89.98^{\circ}$ for the modified film. This result verifies the beneficial role (effect) of the hydrophobic character of D35, stemming from the presence of the butoxy groups that act as an insulating hydrophobic shield, protecting the perovskite absorber. ${ }^{44}$

Subsequently, scanning electron microscopy (SEM) was used to thoroughly examine the effect of the D35 treatment on the perovskite morphology. Fig. 3 shows the perovskite layers with (b and d) and without (a and c) D35 in two different magnifications. The presence of D35 affects the morphology of the perovskite, since the modified films exhibit a smoother surface morphology than the reference one, while the dye seems to polish the surface of the crystals and reduce the area of the grain boundaries. Since the grain boundaries are considered to act as charge recombination sites, their repression entails improved charge transport and collection at the interface of the perovskite film, leading possibly to higher FF value. $^{45}$

The grain size distribution was estimated by the statistical analysis shown in Fig. $\mathrm{S} 7, \dagger$ where the size distribution of a representative $(N=100)$ number of perovskite grains from each sample is presented. The results summarized in Table S2 $\uparrow$ show that in the case of the modified film the mean size of the crystals is slightly larger compared to the reference $(254 \mathrm{~nm}$ versus $240 \mathrm{~nm}$ ). The topology of the films was also examined via atomic force microscopy (AFM) analysis (Fig. 4), which confirmed more homogeneous features with a significant decrease in the surface roughness of the modified perovskite layer $(\mathrm{RMS}=15.9 \mathrm{~nm})$ compared to the reference one $(\mathrm{RMS}=$
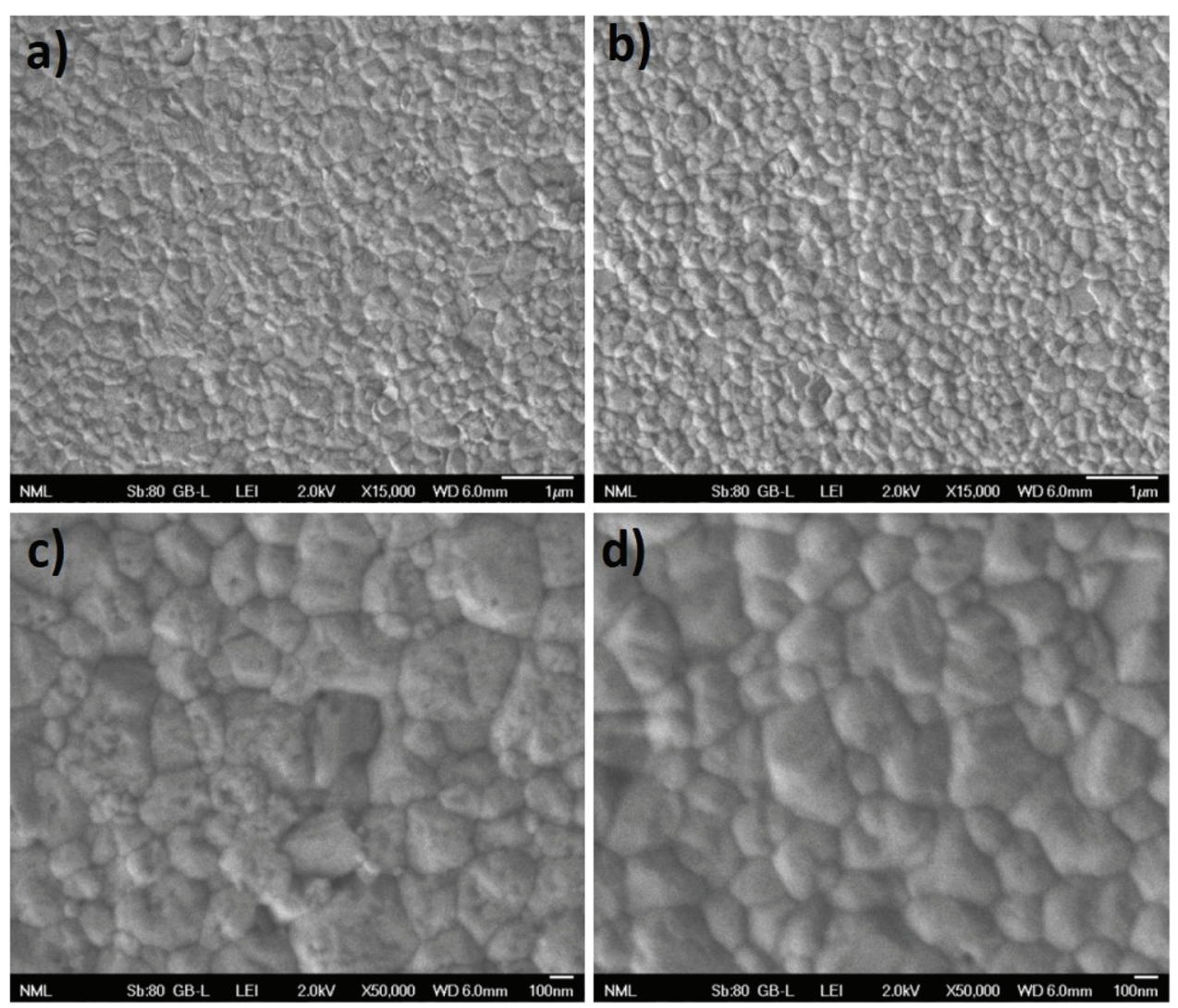

Fig. 3 SEM images of perovskite films without ( $a$ and $c$ ) and with D35 treatment ( $b$ and d) under different magnifications. 

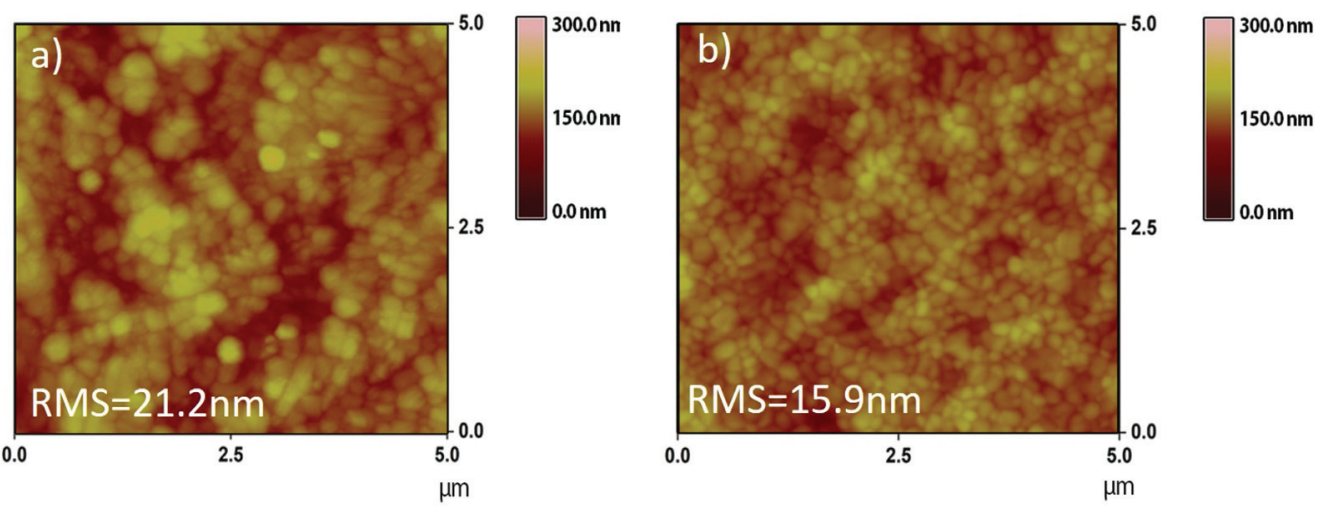

Fig. 4 AFM images of perovskite films without (a) and with D35 treatment (b).

$21.2 \mathrm{~nm})$. Moreover, Fig. $\mathrm{S} 8 \dagger$ shows the depth histograms of the top surface topography with colored scales for the prepared perovskite films, which indicate a significant decrease of the height of surface features (30-120 nm with max: $73.5 \mathrm{~nm}$ for reference to 20-90 nm with max: $50.04 \mathrm{~nm}$ for the D35 PSC).

A decrease in roughness in the case of perovskite films following D35-modification can be attributed to hydrophobic molecules coordinating the perovskite via carboxylic acid binding groups and thus further controlling its crystallization. ${ }^{46}$ Indeed, the obtained results clearly indicate that the presence of D35 atop of the perovskite layer affects the (FA/MA/ Cs) $\mathrm{PbI}_{3-x} \mathrm{Br}_{x} /$ Spiro-MeOTAD interface, leading to a more homogeneous and smoother absorber. Such perovskite films of higher quality and crystallinity are expected to affect the values of current density and fill factor parameters, thus improving the performance of the corresponding PSC devices.
In order to investigate the optoelectronic properties of the employed materials, ultraviolet photoemission spectroscopy (UPS) measurements were performed in samples with and without the D35 chromophore modification. The results are shown in Fig. 5a along with an illustration of the measured and calculated energy bands (Fig. 5b) of the relevant materials.

The energy band gaps were calculated using the data obtained by UV-Vis spectroscopy. The energy level diagram of D35 typically shows the highest occupied molecular orbital (HOMO) level of $5.50 \mathrm{eV}$ and a bandgap of $2.43 \mathrm{eV} .^{33}$ The valence band maxima of (FA/MA/Cs) $\mathrm{PbI}_{3-x} \mathrm{Br}_{x}$ and (FA/MA/Cs) $\mathrm{PbI}_{3-x} \mathrm{Br}_{x} / \mathrm{D} 35$ are located at $5.9 \mathrm{eV}$ and $5.3 \mathrm{eV}$, respectively. This result claims that the presence of D35 affects the position of the energy bands in a way that favors the self-driven charge separation to the hole transporter by reducing the energy barrier, thus facilitates hole transport to the silver electrode via the hole transporting layer. In Fig. 5c, a cross-section SEM
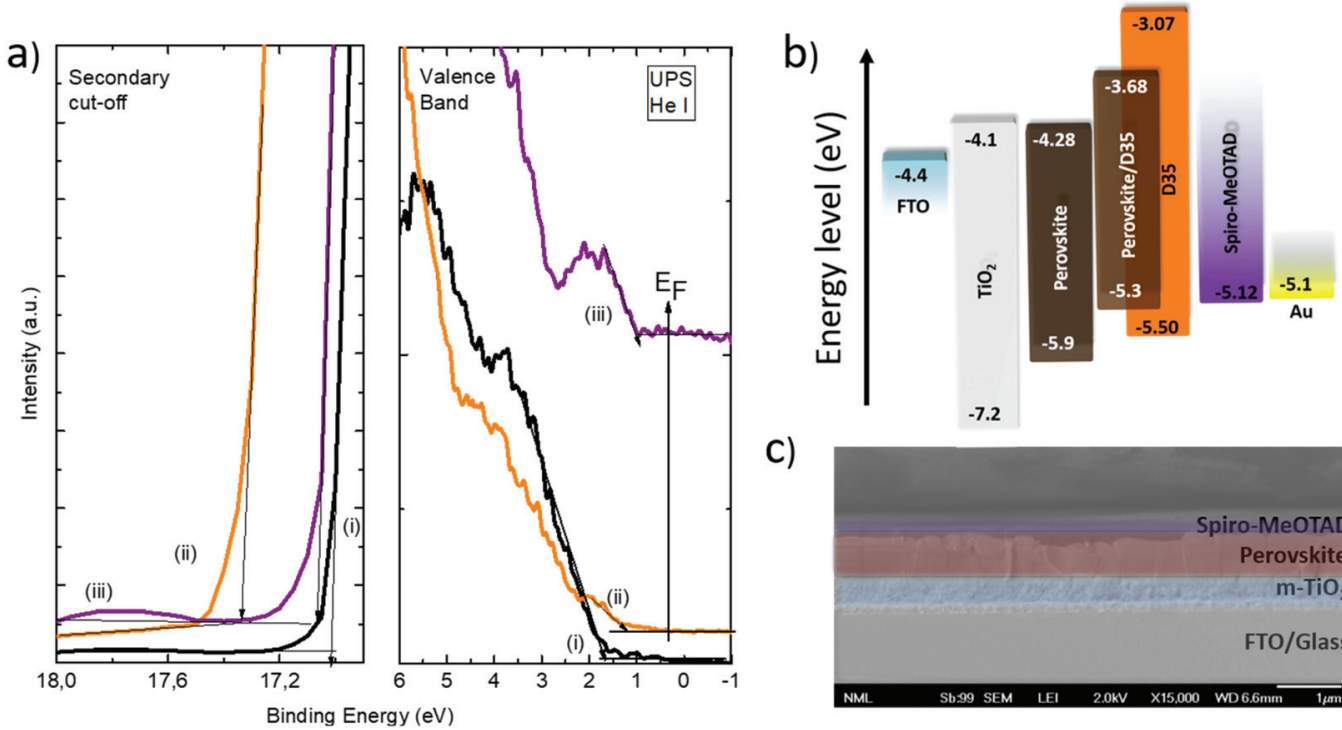

C)

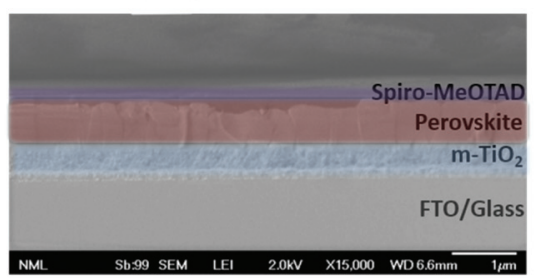

Fig. 5 UPS spectra taken from the surface of (i) ITO/TiO $/$ perovskite, (ii) ITO/TiO $/$ /perovskite/D35, and (iii) ITO/TiO $/ \mathrm{T}_{2}$ perovskite/D35/Spiro-MeOTAD samples. Secondary electron cutoff region and valence band region are depicted (a); the energy level diagram of the materials employed in the PSCs (b). A SEM cross-sectional image of a $\mathrm{TiO}_{2} /$ perovskite/D35/Spiro-MeOTAD device (c). 
image is presented, depicting the successive layers of a D35containing device, built on FTO glass. D35 is not identified while the thickness of the layers is the same in the reference sample also (the corresponding SEM image is not presented). As estimated, the thickness of the (FA/MA/Cs) $\mathrm{PbI}_{3-x} \mathrm{Br}_{x}$ layer is $550 \mathrm{~nm}$, while the thickness of the Spiro-MeOTAD layer and the titania layer is $165 \mathrm{~nm}$ and $390 \mathrm{~nm}$, respectively.

Furthermore, the influence of the donor- $\pi$-acceptor compound in the operation of perovskite solar cells was estimated, thus devices with the following structure were fabricated: FTO/ $\mathrm{TiO}_{2} /$ perovskite/Spiro-MeOTAD/Au denoted as 'Reference PSC' and $\mathrm{FTO} / \mathrm{TiO}_{2} /$ perovskite/D35/Spiro-MeOTAD/Au denoted as 'PSC with D35'. Fig. 6a shows the $J-V$ curves of the champion devices for each batch and Table 1 summarizes the corresponding photovoltaic characteristics.

From these results, it is obvious that D35 improves the performance of the devices and specifically the values of current density and fill factor. Therefore, the maximum efficiency $(18.57 \%)$ was improved by $8.45 \%$ in relation to the reference device. The presence of D35 apparently increased the mean photocurrent which reached a champion value of $24.60 \mathrm{~mA}$ $\mathrm{cm}^{-2}$, while the fill factor was clearly improved from 0.67 for the reference to 0.72 for the best modified PSC. The improved $J_{\text {sc }}$ may be attributed to the higher crystallinity of the D35-containing PSC that leads to increased light harvesting capability of the absorber. Moreover, it implies the existence of improved charge separation and extraction. The fill factor was also improved in the presence of D35, a fact attributed to the improvement of the corresponding interfaces and suppression of the charge recombination process. In addition, the mean $V_{\text {oc }}$ value was also increased, a fact associated with D35's passivation effect along with perovskite's energy band upshifting and lowering of $W_{\mathrm{F}}$ from $4.3 \mathrm{eV}$ to $3.9 \mathrm{eV}$ (Fig. 5a, left part). Finally, a statistical analysis of their photovoltaic performance was performed over 40 devices (Fig. S9†) of each batch, corroborating the superiority of the D35-modified devices.

In order to control the quality of the prepared PSCs, the steady-state PCE (Fig. 6b) was calculated by measuring the cells under 1 sun illumination conditions and constant bias equal to the voltage of the maximum power point $\left(V_{\text {MPP }}\right)$. The $V_{\text {MPP }}$ values for the D35-containing and the reference device are $0.85 \mathrm{~V}$ and $0.83 \mathrm{~V}$, respectively. A PCE value of $18.45 \%$ was stabilized for the modified solar cell after $330 \mathrm{~s}$ of irradiation, which is well consistent with the value taken from the $J-V$ measurements, indicating the robustness of the cells. On the other hand, the stabilized power output for the reference device showed a gradual decline and the corresponding stabilized PCE was lower (15.29\%) than the one obtained from $J-V$ measurements. In addition, internal photo-to-current (IPCE) spectra were recorded for the devices with and without

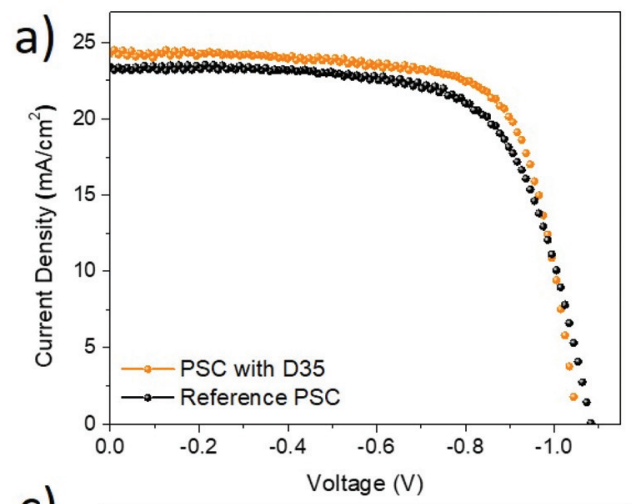

b)
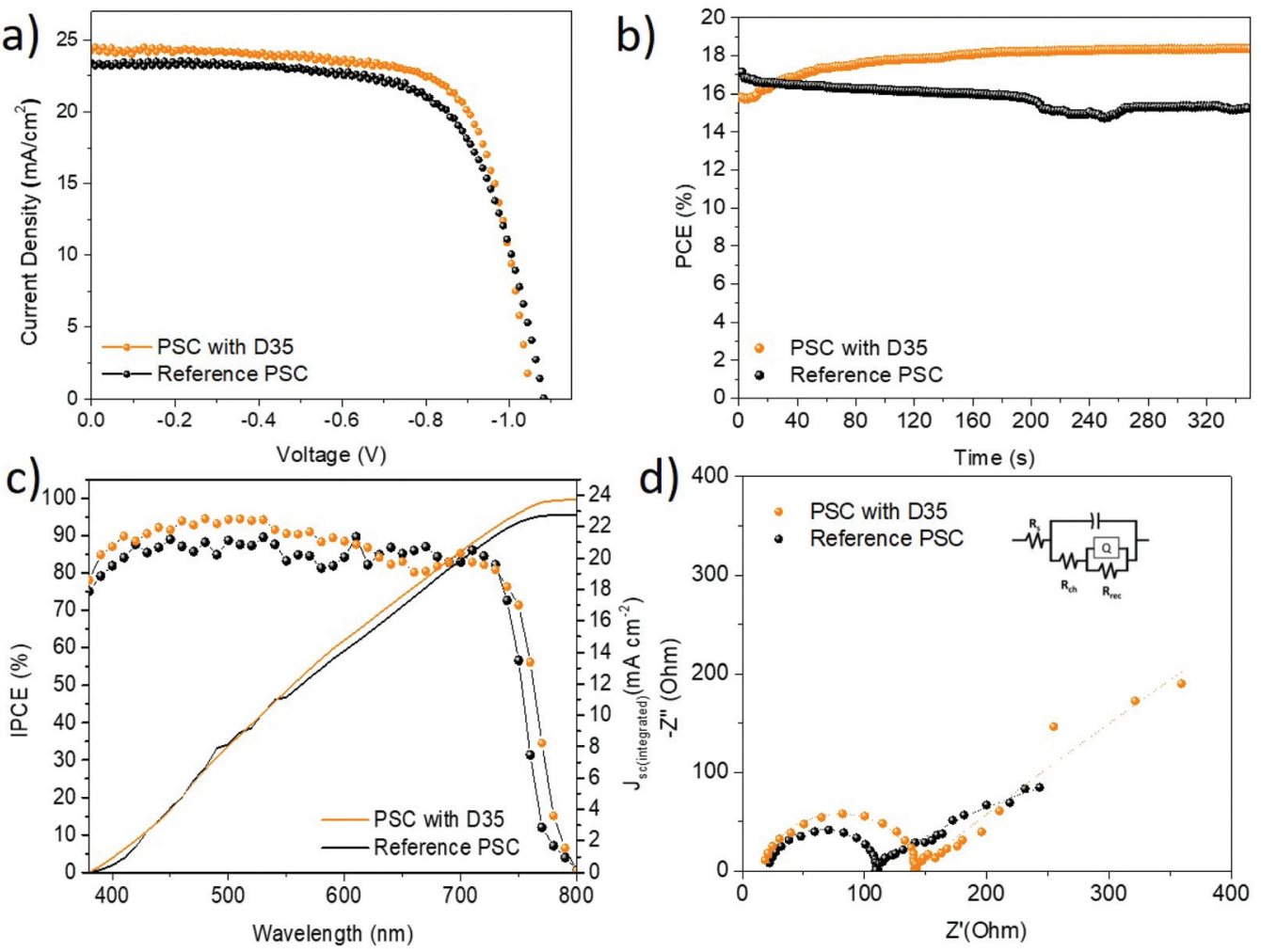

Fig. 6 The $J-V$ curves of the best performing cells with and without D35 (a); the steady-state power conversion efficiency outputs under 1 sun illumination for reference and modified PSCs (b); the IPCE spectra and integration currents of the corresponding PSCs (c); the Nyquist plots obtained via EIS measurements, under 1 sun illumination and under $V_{\text {MPP }}$ bias. Fitting of data is performed using the equivalent electrical circuit in the inset (d). 
Table 1 Photovoltaic parameters for the champion solar cells prepared. Values inside the brackets represent mean values and standard deviations. $V_{\text {oc: }}$ : open-circuit voltage, $J_{\text {sc }}$ : short-circuit current density, FF: fill factor, PCE: power conversion efficiency, and SPCE: stabilized PCE. All data were taken under reverse scan at $50 \mathrm{mV} \mathrm{s}^{-1}$

\begin{tabular}{lllll}
\hline Sample & $J_{\text {sc }}\left(\mathrm{mA} \mathrm{cm}^{-2}\right)$ & $V_{\text {oc }}(\mathrm{V})$ & FF & PCE $(\%)$ \\
\hline Reference PSC & $23.57(22.73 \pm 1.55)$ & $1.08(1.00 \pm 0.07)$ & $0.67(0.62 \pm 0.07)$ & $17.12(14.24 \pm 1.40)$ \\
PSC with D35 & $24.60(23.75 \pm 1.20)$ & $1.05(1.03 \pm 0.06)$ & $0.72(0.65 \pm 0.04)$ & $18.57(15.87 \pm 1.52)$
\end{tabular}

D35 modification, as shown in Fig. 6c. The enhancement of the IPCE in the case of the D35-modified cell is consistent with the corresponding enhancement in the UV spectra. Indeed, the contribution of D35 in the collected photocurrent is important especially below $600 \mathrm{~nm}$, implying that D35 has a strong effect on the charge extraction efficiency of PSCs. The integrated current densities corresponding to $J_{\mathrm{SC}}$ were also calculated to be $23.67 \mathrm{~mA} \mathrm{~cm}{ }^{-2}$ and $22.89 \mathrm{~mA} \mathrm{~cm}^{-2}$ for the devices with and without D35, respectively, values are in relative agreement with those obtained from the $J-V$ curves. Furthermore, the effect of the D35 interface layer on the charge transfer and recombination procedures was estimated by electrochemical impedance spectroscopy (EIS) measurements, carried out in PSCs with and without D35. The experiments were carried out under dark and light conditions ( 1 sun illumination), while the devices were biased at the $V_{\text {MPP }}$ values. The corresponding plots are shown in Fig. 6d and Fig. S10,$\dagger$ whereas the extracted parameters are summarized in Table 2.

In the Nyquist plots (obtained under illumination Fig. 6d), we denote the appearance of two arcs which are associated with charge transfer (the low-frequency semicircle) and charge recombination (the high-frequency semicircle) processes. ${ }^{57,58}$ The obtained parameters summarized in Table 2 show that the series $\left(R_{\mathrm{s}}\right)$ and charge transfer $\left(R_{\mathrm{ch}}\right)$ resistances are reduced in the presence of D35, while recombination resistance $\left(R_{\text {rec }}\right)$ of the D35-containing PSC is significantly higher than that of the reference solar cell. The higher $R_{\text {rec }}$ manifests a lower recombination rate, while under dark conditions the results (Table 2 and Fig. $\mathrm{S} 10 \dagger)$ also confirm that all resistive parameters $\left(R_{\mathrm{s}}, R_{\text {rec }}\right.$, and $R_{\mathrm{ch}}$ ) are improved in the presence of $\mathrm{D} 35$, affirming its beneficial effect to the device performance.

It has been demonstrated that the introduction of semiconducting molecules contributes to the efficient charge separation and extraction along perovskite grain boundaries. ${ }^{47}$ In this context, the incorporation of the D- $\pi-\mathrm{A}$ D35 organic compound should enhance the charge extraction across the photoexcited perovskite layer and thus eventually decrease the possibility of recombination. Steady-state and time-correlated single

Table 2 Ohmic resistance values obtained from the EIS analysis of PSCs based on the D35 interlayer, in comparison to reference devices

\begin{tabular}{lllll}
\hline & Sample & $R_{\mathrm{s}}(\mathrm{Ohm})$ & $R_{\mathrm{ch}}(\mathrm{Ohm})$ & $R_{\text {rec }}(\mathrm{Ohm})$ \\
\hline Dark & PSC with D35 & 154.2 & 8322 & $4.3 \times 10^{6}$ \\
& Reference PSC & 281.8 & 9663 & $7.5 \times 10^{5}$ \\
Light & PSC with D35 & 17.9 & 85.1 & 5980 \\
& Reference PSC & 22.5 & 122.4 & 561
\end{tabular}

photon counting (TCSPC) fluorescence spectroscopy studies enabled the investigation of these electronic interactions taking place in the different device configurations under photoexcitation.

Initially, the $\mathrm{FTO} / \mathrm{TiO}_{2} /$ perovskite/D35 device was examined with respect to the $\mathrm{FTO} / \mathrm{TiO}_{2} /$ perovskite employed as the reference (Fig. S11a and $\mathrm{b} \dagger$ ). Under photoexcitation at 482 and $650 \mathrm{~nm}$, the emission intensity of the perovskite was found quenched by 75 and $45 \%$, respectively, suggesting that the incorporation of the D35 dye decreases the recombination yield in the perovskite layer, hence highlighting an increased yield of electron-hole separation. More specifically, the transfer of the photogenerated holes across the perovskite layer to the HOMO level of the $\mathrm{Pb}^{2+}$-coordinated D35 molecules is expected, accompanied by the injection of electrons from D35 to the perovskite. It is known that the selected dye molecule has excellent electron injection properties, while the butoxy chains present on the triphenylamine core probably prevent the photogenerated electrons located on the perovskite from radiative recombination due to their insulating character. ${ }^{48-50} \mathrm{~A}$ slight red-shift observed to the PL maxima of the $\mathrm{FTO} / \mathrm{TiO}_{2} /$ perovskite/D35 device may represent the electron-hole recombination process at the perovskite/D35 interface. Interestingly, the $75 \%$ quenching recorded under $480 \mathrm{~nm}$ excitation indicates an improved charge separation in the spectral region where both the perovskite and the dye absorb light. This fact is also evident at the IPCE spectra shown in Fig. 6c, where for $\mathrm{FTO} / \mathrm{TiO}_{2} /$ perovskite/D35/Spiro-MeOTAD a broad shoulder at around $500 \mathrm{~nm}$ is present, contrasting the reference ones obtained without the organic dye.

As far as the time-resolved PL spectra recorded for the FTO/ $\mathrm{TiO}_{2} /$ perovskite/D35 device are concerned (Fig. S11c $\dagger$ ), the average emission lifetime of the photoexcited perovskite was found to be $1.87 \mathrm{~ns}$, increased by a factor of 0.4 as compared to the $1.32 \mathrm{~ns}$ emission lifetime recorded for the reference $\mathrm{FTO} / \mathrm{TiO}_{2} /$ perovskite device (Table 3 ). We assume a synergistic

Table 3 Biexponential fitting of the perovskite's fluorescence emission decay traces recorded via time-correlated single photon counting (TCSPC) spectroscopy under $482 \mathrm{~nm}$ excitation at room temperature probed at $750 \mathrm{~nm}$ ( $t$ : decay lifetime and $A$ : relative population)

\begin{tabular}{llllll}
\hline Device & $\begin{array}{l}t_{1} \\
\text { (ns) }\end{array}$ & $A_{1}$ & $\begin{array}{l}t_{2} \\
\text { (ns) }\end{array}$ & $A_{2}$ & $\begin{array}{l}\text { Average } \\
\text { (ns) }\end{array}$ \\
\hline $\mathrm{TiO}_{2} /$ perovskite & 4.2 & 0.27 & 0.256 & 0.73 & 1.32 \\
$\mathrm{TiO}_{2} /$ perovskite/D35 & 3.9 & 0.42 & 0.395 & 0.58 & 1.87 \\
$\mathrm{TiO}_{2} /$ perovskite/Spiro-MeOTAD & 2 & 0.58 & 0.194 & 0.42 & 1.20 \\
$\mathrm{TiO}_{2} /$ perovskite/D35/Spiro- & 1.85 & 0.37 & 0.215 & 0.63 & 0.83 \\
$\mathrm{MeOTAD}$ & & & & &
\end{tabular}


effect, where the incorporation of D35 at $\mathrm{Pb}^{2+}$ edges (a) furnishes a passivation effect to the exciton traps arise from peripheral crystal imperfections, and (b) retards the electron-hole recombination due to its bulk and insulating chemical structure. ${ }^{51}$ Furthermore, we investigated the steady-state and timeresolved fluorescence profiles for $\mathrm{FTO} / \mathrm{TiO}_{2} /$ perovskite/SpiroMeOTAD and $\mathrm{FTO} / \mathrm{TiO}_{2} /$ perovskite/D35/Spiro-MeOTAD devices, in comparison to $\mathrm{FTO} / \mathrm{TiO}_{2} /$ perovskite employed as the reference. Upon photoexcitation, the emission (at two wavelengths, i.e. 480 and $650 \mathrm{~nm}$ ) of the perovskite layer was greatly quenched (especially by $98 \%$ under $480 \mathrm{~nm}$ excitation - Fig. 7a and b). Although no spectral shifts were evident in the PL spectra of $\mathrm{FTO} / \mathrm{TiO}_{2} /$ perovskite/Spiro-MeOTAD, as compared to FTO/TiO $/$ perovskite, for $\mathrm{FTO}_{2} / \mathrm{TiO}_{2} /$ perovskite/D35/SpiroMeOTAD a blue-shift of around $7 \mathrm{~nm}$ was clearly detected under $480 \mathrm{~nm}$ excitation (and $2 \mathrm{~nm}$ under $680 \mathrm{~nm}$ excitation). As long as the hole-transport layer of spiro-MeOTAD accelerates the extraction of the photogenerated holes from the perovskite layer through the perovskite/D35 interface, recombination of electron-hole pairs mostly occurs in the bulk domains of the perovskite layer. The blue-shifted emission maxima for the $\mathrm{FTO} / \mathrm{TiO}_{2} /$ perovskite/D35/Spiro-MeOTAD device, located at $743 \mathrm{~nm}$, illustrate enhanced charge recombination from the uniform crystal domains of the perovskite, manifesting a decrease in charge recombination events due to surface trap states. ${ }^{52}$ Furthermore, it is also related to the conduction and valence band edges filled by the photogenerated carriers, thus allowing transitions of higher energy. ${ }^{53}$ Eventually, the reference $\mathrm{FTO} / \mathrm{TiO}_{2}$ /perovskite/Spiro-MeOTAD showed no spectral shifts since the Spiro-MeOTAD layer is not beneficial for the surface trap state engineering of the perovskite layer. Having in mind the earlier discussed redshift in the PL spectra observed for the $\mathrm{FTO} / \mathrm{TiO}_{2} /$ perovskite/ D35 devices, we conclude that the exciton recombination maxima of the perovskite centered at $750 \mathrm{~nm}$ constitute a gross emission fingerprint of the recombination events taking place at (a) the surface trap states (around $755 \mathrm{~nm}$ ) and (b) the bulk uniform crystal domains (around $744 \mathrm{~nm})^{50}$
Next, we assessed the emission time-resolved decay of the perovskite layer in the $\mathrm{FTO} / \mathrm{TiO}_{2} /$ perovskite/SpiroMeOTAD and FTO/TiO $/$ /perovskite/D35/Spiro-MeOTAD devices under $480 \mathrm{~nm}$ excitation (Fig. 7c). The average $1.87 \mathrm{~ns}$ fluorescence lifetime of the perovskite layer, composed of two populations of $4.2 \mathrm{~ns}(27 \%)$ and $256 \mathrm{ps}$ (73\%), was decreased by the addition of the Spiro-MeOTAD layer, affording an average lifetime of $1.2 \mathrm{~ns}$, also composed of two populations of $2 \mathrm{~ns}(58 \%)$ and $194 \mathrm{ps}$ (42\%), in the $\mathrm{FTO} / \mathrm{TiO}_{2} /$ perovskite/ Spiro-MeOTAD device. In line with the steady-state PL spectroscopy findings, the incorporation of Spiro-MeOTAD enhances the extraction of the photogenerated charges, hence leading to an acceleration of the perovskite's PL lifetime decay due to the fast hole transfer process. A further decrease in the $\mathrm{PL}$ lifetime was recorded for the $\mathrm{FTO} / \mathrm{TiO}_{2} /$ perovskite/D35/ Spiro-MeOTAD device, where the D35-passivated perovskite interfaced the Spiro-MeOTAD, resulting in an average emission lifetime of $820 \mathrm{ps}$, based on the bi-exponential fitting of the decay trace with two components of 1.85 ns (37\%) and 215 ps $(63 \%)$.

In order to shed more light on the effect of the D35 compound, steady-state and time-resolved PL experiments were performed, albeit using plain glass substrates upon which successively perovskite, D35, and Spiro-MeOTAD layers were coated. The FTO and $\mathrm{TiO}_{2}$ layers were excluded as to isolate the charge transport influence of the D35 interlayer. Initially, the deeply penetrating $650 \mathrm{~nm}$ laser was utilized to investigate the charge transport properties of the D35 dye in devices consisting of perovskite layers coated directly in plain glass substrates, by irradiating the samples from both the surface and the glass backside (Fig. S12 $\dagger$ ). In both cases, the PL emission of the perovskite was found quenched, underscoring the good charge transport properties of D35. Nevertheless, a broad emission trace was recorded when irradiation was performed from the glass side, revealing that in the absence of the $\mathrm{TiO}_{2}$ layer the perovskite is not uniformly distributed at the glass/ perovskite interface. In contrast, irradiation at the perovskite surface side suggests a better crystal growth and morphology as realized by the symmetric well-defined exciton recombina- a)

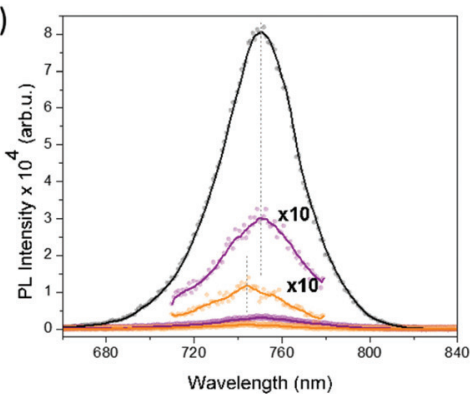

b)

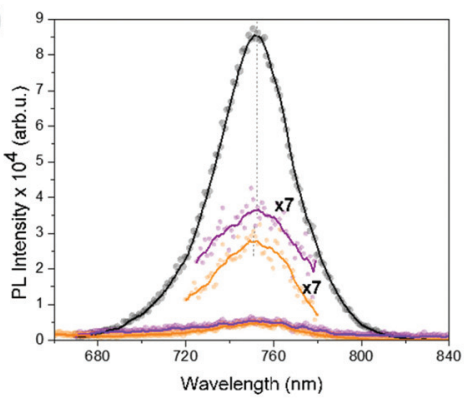

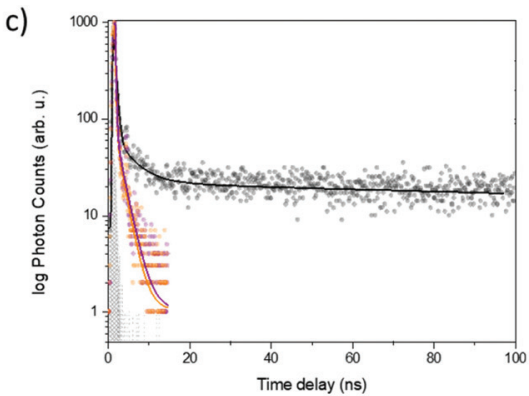

Fig. 7 Steady-state photoluminescence spectra of $\mathrm{FTO} / \mathrm{TiO}_{2} /$ perovskite (black), $\mathrm{FTO} / \mathrm{TiO}_{2} /$ perovskite/Spiro-MeOTAD (purple) and FTO/TiO $/$ perovskite/D35/Spiro-MeOTAD (orange) devices at room temperature upon excitation at (a) $482 \mathrm{~nm}$ and (b) $650 \mathrm{~nm}$. (c) Time-correlated single photon counting spectra under $482 \mathrm{~nm}$ excitation probed at $750 \mathrm{~nm}$ obtained at room temperature. 
tion peak. Also, a slightly blue-shifted emission peak was evident in the presence of D35, suggesting the trap-state passivation role of the organic molecule. Irradiating the surface side of the glass/perovskite reference device with 482 and $650 \mathrm{~nm}$, a maximum PL emission at 755 and $758 \mathrm{~nm}$, respectively, was detected (Fig. S13a and $\mathrm{b} \dagger$ ). These red-shifted bands, as compared to those obtained in the $\mathrm{FTO} / \mathrm{TiO}_{2} /$ perovskite device, are probably related to the slightly different morphology of the perovskite layer on the glass, as compared to the $\mathrm{FTO} / \mathrm{TiO}_{2}$ substrate. Incorporation of the D35 compound resulted in a blue shift of $2 \mathrm{~nm}$ and significant quenching of the recorded emission spectra, both under 480 and $650 \mathrm{~nm}$ excitations. Moreover, the recorded PL lifetimes revealed a faster deactivation for the perovskite layer interfacing the D35 dye (Table S3†). Eventually, the coordination of the D35 dye at the $\mathrm{Pb}^{2+}$ edges via the cyanoacrylic acid anchoring group passivates the crystal imperfections. Thus, in the absence of the electron transport layer, the band edges of the perovskite are populated with charges leading to a faster recombination of the photogenerated excitons from the bulk.

The passivating effect of D35 was further examined by characterizing electron-only devices in the space-chargelimited-current (SCLC) regime. $^{54}$ Fig. 8 shows the $I-V$ response, measured for devices fabricated with the following structure: $\quad \mathrm{FTO} / \mathrm{TiO}_{2} / \mathrm{MAFACsPbI}_{3-x} \mathrm{Br}_{x} / \mathrm{PCBM}_{60} / \mathrm{Ag}$ corresponding to the reference device and $\mathrm{FTO} / \mathrm{TiO}_{2} /$ MAFACsPbI $_{3-x} \mathrm{Br}_{x} / \mathrm{D} 35 / \mathrm{PCBM}_{60} / \mathrm{Ag}$ corresponding to the D35containing one. At low voltage values, the $I-V$ plot is ohmic, while in mid-range values the current shows a rapid nonlinear increase, characterized by the transition to the trap filled limit (TFL) regime where all the available trap states are filled by the injected carriers. At high voltage values (not shown clearly due to the relative instability of the devices), the current shows a quadratic dependence against voltage (Child's regime). ${ }^{55}$ As reported elsewhere, ${ }^{56}$ the ohmic to TFL transition point $\left(V_{\mathrm{TFL}}\right)$ is related to the trap density $\left(N_{\mathrm{t}}\right)$, according to the following eqn (2 ):

$$
V_{\mathrm{TFL}}=\frac{e N_{\mathrm{t}} d^{2}}{2 \varepsilon \varepsilon_{0}}
$$

where $e$ is the elementary charge, $d$ is the thickness of the active layer $(550 \mathrm{~nm}), \varepsilon$ is the dielectric constant $(\varepsilon=28.8)^{57}$ and $\varepsilon_{0}$ is the dielectric constant under vacuum. The calculated trap density $\left(N_{\mathrm{t}}\right)$ is $3.2 \times 10^{15} \mathrm{~cm}^{-3}$ for the reference device and $1.9 \times 10^{15} \mathrm{~cm}^{-3}$ for the modified one, respectively. These results, confirming the PL measurements, indicate that the presence of D35 reduces the perovskite trap states.

Moreover, Fig. 8b shows the corresponding XRPD patterns of perovskite films with and without D35 coated upon $\mathrm{TiO}_{2}$, as prepared and after two months of storage under ambient and dark conditions $(\mathrm{RH}=25 \%$, without encapsulation). The XRPD analysis of reference films shows extra peaks at $2 \theta=$ $\left(12.45^{\circ}, 25.02^{\circ}\right.$, and $29.22^{\circ}$ ) corresponding to $\mathrm{PbI}_{2}, \mathrm{PbO}$ (PDF 77-1971), and PbOHI (PDF 75-1177), respectively, thus confirming the progressive degradation of the reference film due to the thermodynamic and humidity effect which leads to a change in the chemical composition and phase transition of the perovskite. Despite some presence of $\mathrm{PbI}_{2}$ at the modified film, the hydrophobic character of D35 decreased the effect of humidity on the perovskite layer. The latter was also confirmed by X-ray photoelectron spectroscopy (XPS) measurements (Fig. 8c), whereas the $\mathrm{C}=\mathrm{O}$ peak $(288.1 \mathrm{eV})$ seen for the control film associated with oxygen/moisture is significantly suppressed after D35 modification, indicating that the D35 interlayer can slow the degradation of the perovskite layer. ${ }^{58}$ In the case of a dense D35 layer $\left(10^{-2} \mathrm{M}\right)$, the peak completely vanished.

Finally, the stability of the cells was evaluated by storing the cells (in the dark) and periodically measuring their $J-V$ characteristics. The PSCs were stored unsealed in a desiccator under dark and relatively humid conditions $(\mathrm{RH}=25 \%)$. The results are shown in Fig. 9, where the main photovoltaic parameters are plotted against time.

After 37 days, the PSCs with D35 preserved 83\% of their initial PCE. This is mainly attributed to the stabilization of FF which only declined by $2 \%$ concerning the initial value and secondly to the evolution of $J_{\mathrm{sc}}$ which decreased by $5 \%$ compared to the starting point. Both values are improved in comparison with the reference PSC, which preserved $77 \%$ of its
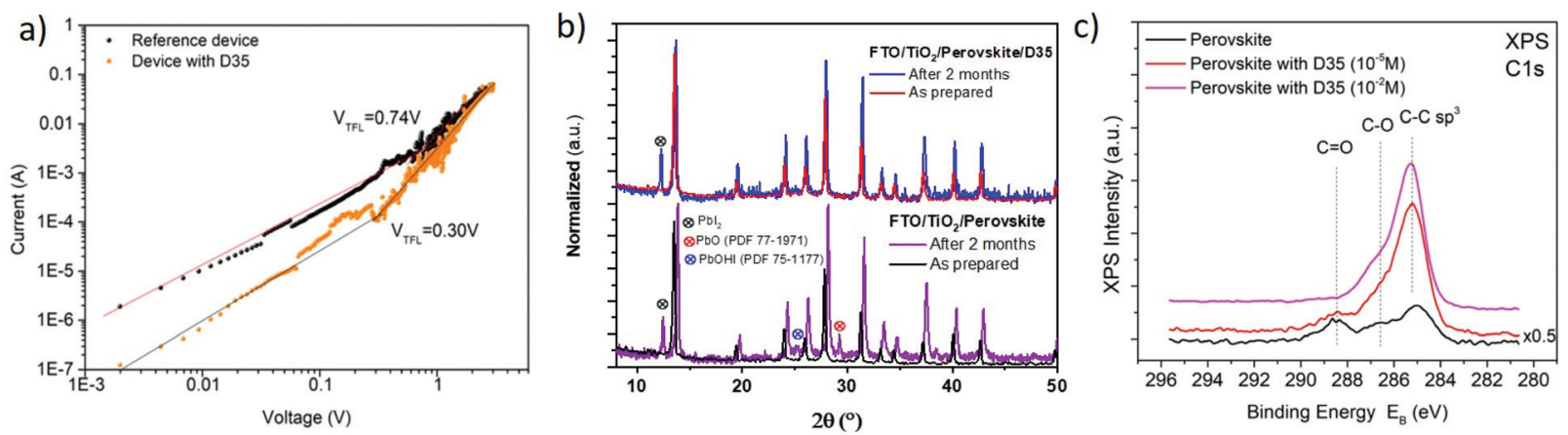

Fig. 8 The $I-V$ curves for electron-only devices with and without D35 (a); XRPD patterns of fresh and aged perovskite films with and without D35 treatment (b); and XPS measurements for perovskite films without and with D35 in two different concentrations $\left(10^{-5} \mathrm{M}^{2}\right.$ and $\left.10^{-2} \mathrm{M}\right)(\mathrm{c})$. 

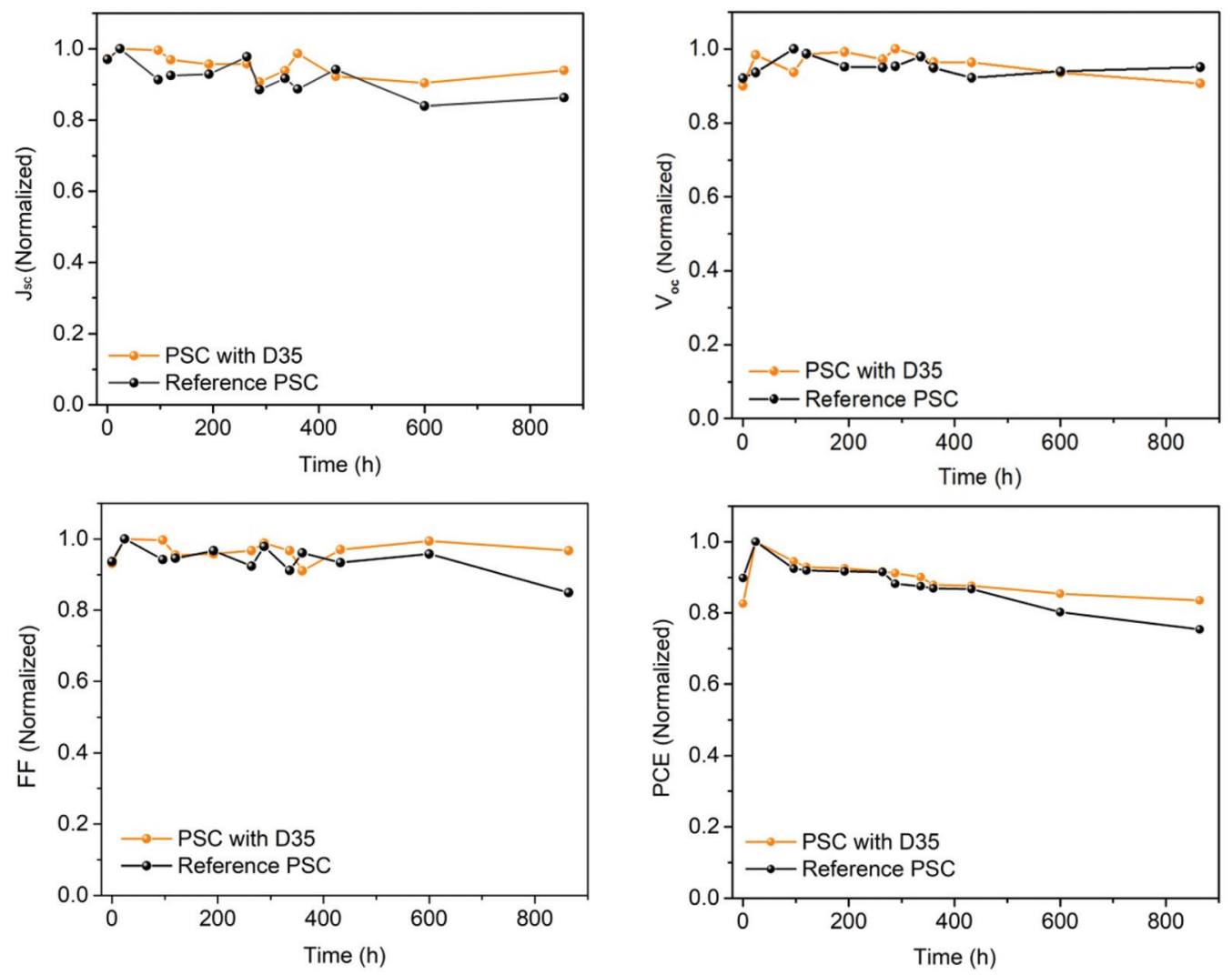

Fig. 9 Evolution of the main photovoltaic parameters over time for PSCs with and without D35.

original PCE, a value lower by $11.5 \%$ than the modified device. In contrast, the value of $V_{\mathrm{oc}}$ was practically unaffected by the presence of D35 since it is almost stable after $890 \mathrm{~h}$ of storage.

\section{Conclusions}

In conclusion, an effective versatile strategy for enhancing perovskite device performance using the D35 donor- $\pi$-acceptor was introduced. The D35 treatment improves perovskite film crystallization, enhances light absorption and provokes an appropriate energy alignment that favors charge extraction to the anode and cathode electrodes. ESP analysis suggests that D35 possesses a carboxylate group with high electron density, which could coordinate/passivate with the undercoordinated $\mathrm{Pb}^{2+}$ cations of the perovskite crystals, thus retarding nonradiative recombination. At the other end of the D35 molecule, hydrophobic butoxy chains improve the moisture stability of the perovskite films. PSCs with the D35 interlayer showed the best PCE of $18.57 \%$, while unencapsulated modified devices retain $83 \%$ of their initial PCE after storage in a desiccator for 37 days, while the PCE of the reference devices degraded to $77 \%$ after aging procedure. This work elaborates on a novel strategy to combine $\mathrm{D}-\pi$-A organic dyes with perovskites to fabricate robust perovskite films for efficient and stable PSCs.

\section{Experimental section}

\section{Materials and device fabrication}

All reagents including titanium diisopropoxide bis(acetylacetonate), lead iodide $\left(\mathrm{PbI}_{2}\right)$, lead bromide $\left(\mathrm{PbBr}_{2}\right)$, methylammonium bromide (MABr), formamidinium iodide (FAI), dimethylformamide (DMF), dimethyl sulfoxide (DMSO), acetonitrile, anhydrous chlorobenzene and 4-tert-butylpiridine (TBP) were obtained from Sigma-Aldrich. Lithium bis(trifluoromethylsulphonyl)imide (Li-TFSI) was purchased from Acros, $\mathrm{Co}[t-\mathrm{BuPyPz}]_{3}[\mathrm{TFSI}]_{3}$ from Sigma-Aldrich, FK209 and $\mathrm{TiO}_{2}$ $30 \mathrm{~N}-\mathrm{RD}$ paste from Dyesol, and D35 from Dyenamo AB. FTO conductive glass electrodes ( $7 \mathrm{ohm}$ per sq) were cleaned by ultrasounds (successively with Hellmanex 2\% (v/v) in deionized water, ethanol, isopropanol and acetone for $15 \mathrm{~min}$ each step). Finally, the conductive substrates were rinsed with isopropanol and dried using $\mathrm{N}_{2}$ flow. Then the cleaned glasses were treated with UV-ozone for $15 \mathrm{~min}$. Immediately after cleaning, the $\mathrm{TiO}_{2}$ compact layer $\left(\mathrm{c}-\mathrm{TiO}_{2}\right)$ was deposited using spray pyrolysis of titanium diisopropoxide bis(acetylacetonate) diluted in ethanol on substrates, followed by $1 \mathrm{~h}$ annealing at $450{ }^{\circ} \mathrm{C}$. Afterwards, a mesoporous layer of $\mathrm{TiO}_{2}\left(\mathrm{~m}-\mathrm{TiO}_{2}\right) 30$ $\mathrm{N}-\mathrm{RD}\left(150 \mathrm{mg} \mathrm{mL}^{-1}\right)$ was spin-coated at $4000 \mathrm{rpm}$ for $20 \mathrm{~s}$, followed by immediate drying at $125^{\circ} \mathrm{C}$ for 5 minutes, and sintering at $325^{\circ} \mathrm{C}, 375^{\circ} \mathrm{C}$, and $450{ }^{\circ} \mathrm{C}$ for $5 \mathrm{~min}, 5 \mathrm{~min}$ and $30 \mathrm{~min}$, respectively. The perovskite film was deposited in an Ar-filled 
glovebox by spin coating upon the $\mathrm{TiO}_{2}$ substrates. The perovskite precursor solution was prepared using $1.1 \mathrm{M} \mathrm{PbI}_{2}, 0.2 \mathrm{M}$ $\mathrm{PbBr}_{2}, 1 \mathrm{M}$ FAI and $0.2 \mathrm{M} \mathrm{MABr}$ in an $850 \mu \mathrm{l}$ aliquot of mixed DMSO : DMF (1:4, volume ratio) solvent. $50 \mu$ l of CsI (1.5 M stock solution) was added to the perovskite solution which was spin-coated at $1000 \mathrm{rpm}$ for $10 \mathrm{~s}$ and continuously at $6000 \mathrm{rpm}$ for $20 \mathrm{~s}$. In addition, $150 \mu \mathrm{L}$ of anhydrous chlorobenzene (for the reference PSC) was poured on the perovskite film $7 \mathrm{~s}$ prior to the end of process (anti-solvent treatment). When D35 was used during anti-solvent treatment, it was poured and dissolved in anhydrous chlorobenzene $\left(10^{-5} \mathrm{M}\right)$. When D35 was used as an extra interlayer upon perovskite, $150 \mu \mathrm{L}$ of D35 diluted in anhydrous chlorobenzene $\left(10^{-3}, 10^{-4}, 10^{-5}\right.$, and $10^{-6} \mathrm{M}$ ) was poured on the film with the same strategy as for the reference films, followed by post-annealing at $100{ }^{\circ} \mathrm{C}$ for $45 \mathrm{~min}$. After cooling down to room temperature, SpiroMeOTAD was spin-coated at $4000 \mathrm{rpm}$ for $20 \mathrm{~s}$. The $70 \mathrm{mM}$ Spiro-MeOTAD solution was prepared using anhydrous chlorobenzene. In addition, Li-TFSI in acetonitrile, 4-tert-butylpyridine, and FK209 in acetonitrile were added at a molar ratio of Spiro-MeOTAD : TBP : Li-TFSI : FK209 = $1: 3.3: 0.5: 0.03$. Finally, the devices were completed with thermal evaporation of $60 \mathrm{~nm}$ of $\mathrm{Au}$ as counter electrodes.

\section{Characterization}

X-ray powder diffraction (XRPD) analysis was carried out on a Siemens D-500 diffractometer, operating in Bragg-Brentano geometry with $\mathrm{Cu}-\mathrm{K} \alpha 1(\lambda=1.5406 \AA)$ and $\mathrm{Cu}-\mathrm{K} \alpha 2(\lambda=$ $1.5444 \AA)$ radiation. Data were collected over the angular range $5^{\circ} \leq 2 \theta \leq 80^{\circ}$ counting for 3 seconds at each step of $0.02^{\circ}$ in detector position. Absorption and diffuse reflectance $(R)$ spectra of the perovskite materials (in the form of $1 \mathrm{~mm}$ thick pellets) were recorded on a Hitachi U-3010 UV-Vis spectrophotometer, equipped with an integrating sphere and the obtained data were transformed in Kubelka-Munk $F(R)$ units as: $F(R)=(1-R)^{2} / 2 R$. The sample morphologies were investigated using a FESEM (JEOL 7401f). Atomic Force Microscopy (AFM) images were obtained with an AFM: Digital Instruments Nanoscope III, operating in tapping mode. Surface analysis measurements (XPS/UPS) were performed in a UHV chamber $\left(P \sim 5 \times 10^{-10} \mathrm{mbar}\right)$, equipped with a SPECS Phoibos 100-1D-DLD hemispherical electron analyzer, a nonmonochromatized dual-anode $\mathrm{Mg} / \mathrm{Al} \mathrm{X}$-ray source for XPS and a UV source (model UVS 10/35) for UPS. The XP spectra were recorded with $\mathrm{MgKa}$ at $1253.6 \mathrm{eV}$ photon energy and an analyzer pass energy of $10 \mathrm{eV}$ giving a Full Width at Half Maximum (FWHM) of $0.85 \mathrm{eV}$ for $\mathrm{Ag} 3 \mathrm{~d}_{5 / 2}$ line. The UPS spectra were obtained using HeI irradiation with $h \nu=21.22 \mathrm{eV}$ where the analyzer was working in the Constant Retarding Ratio (CRR) mode, with $\mathrm{CRR}=3$. From the UPS spectra, the Ionization Potential or the High Occupied Molecular Orbital (HOMO) is derived from the sum of the work function (WF) and the Valence Band Maximum (VBM) cut-off derived by linear extrapolation towards background in the low and high binding energy regions, as shown in Fig. 5a. The analyzed area was a $3 \mathrm{~mm}$ diameter spot. The films for the UPS measurements, including the $\mathrm{ITO} / \mathrm{c}-\mathrm{TiO}_{2} / \mathrm{m}-\mathrm{TiO}_{2} /$ perovskite/D35 structure, were prepared in the glovebox. In an $\mathrm{Ar}$ atmosphere, the samples were introduced and stored in a sealed box which was kept in the dark. Just before analysis, the samples were carefully removed from the box under argon and were directly introduced in the UHV chamber for the UPS measurements, thus avoiding surface contamination and/or modification. Steady-state emission spectra were recorded on a Horiba Fluorolog-3 Jobin-Yvon Spex spectrofluorometer (model GL321), equipped with a $450 \mathrm{~W}$ Xe lamp as an excitation source and a TBX photomultiplier (250-850 nm) as a detector. Data were recorded and collected using the Horiba Fluorescence V3 software. For the picosecond time-resolved fluorescence spectra, a time-correlated single photon counting (TCSPC) method using a FluoroHub single photon counting controller, a laser diode as an excitation source (NanoLED, $482 \mathrm{~nm}$, pulse duration $<200 \mathrm{ps}$ ) and a TBX-PMT detector (250-850 nm), all by Horiba Jobin Yvon, was applied. Data were recorded and collected using the Data Station software, whereas the lifetimes were determined using the Data Acquisition Software (DAS), all provided by Horiba. The spectra were recorded on thin films over FTO-coated glass substrates, with the aid of a FL-1057 sample holder. The solar cell performance was determined using a Xenon $300 \mathrm{~W}$ source solar simulator in combination with AM 1.5G optical filters (1 sun). The light intensity was calibrated with a $\mathrm{Si}$ reference cell. Current density-voltage $(J-V)$ characteristics were obtained using an Autolab potentiostat (PGSTAT-302N) at a scan rate of $150 \mathrm{mV} \mathrm{s}^{-1}$ and the illuminated (active) area was set to $0.10 \mathrm{~cm}^{2}$. The $J-V$ curves were obtained by illuminating the solar cells under a Solar Light Co. $300 \mathrm{~W}$ Air Mass Solar Simulator Model 16S-300 (1 sun, $1000 \mathrm{~W} \mathrm{~m}^{-2}$ ) calibrated using an OptoPolymer Si reference cell. The measurements were carried out using Ossila's Push-Fit Test Board for Photovoltaic Substrates. Impedance measurements (EIS) were performed on complete cells under dark and 1 sun illumination conditions, by applying forward bias at $V_{\mathrm{MPP}}$, using the PG-STAT-30 potentiostat and its built-in frequency response analyzer (FRA). ESP analysis was performed by density functional theory (DFT) using the Gaussian 09 computational package. The calculation was carried out using CAM-B3LYP as a calculation method, basis set $=6-31 \mathrm{G}(\mathrm{d}, \mathrm{p})$ with ethanol as a solvent. Contact angle measurements were performed using a Contact Angle Meter (CAM) 100, KSV Instruments, Ltd. FTIR spectra were collected in transmission mode on a Thermo Scientific Nicolet 6700 FTIR, equipped with an $\mathrm{N}_{2}$ purging system using $\mathrm{KBr}$ pellets. A total of 32 scans were averaged for each sample at a resolution of $4 \mathrm{~cm}^{-1}$. Data were collected in the range of $4000-400 \mathrm{~cm}^{-1}$ and corrected against the singlebeam spectrum of $\mathrm{KBr}$.

\section{Conflicts of interest}

There are no conflicts to declare. 


\section{Acknowledgements}

This work was supported by the European Union's Horizon 2020 Marie Curie Innovative Training Network 764787 "MAESTRO” project. The authors are grateful to Dr G. Manolis and Dr F. Katsaros for their assistance in the titania spray pyrolysis deposition and the FTIR measurements, respectively. Moreover, the authors would like to thank M.C. Skoulicidou [Nanotechnology and Microsystems Laboratory (NML) of the Institute of Nanoscience and Nanotechnology at NCSR 'Demokritos' in Greece] for taking the SEM pictures and Dr A. Kaltzoglou for taking the XRPD patterns. M. Elsenety is thankful to the Greek Ministry of Foreign Affairs and the Egyptian Government for his PhD Scholarship.

\section{References}

1 A. Kojima, K. Teshima, Y. Shirai and T. Miyasaka, J. Am. Chem. Soc., 2009, 131, 6050.

2 H. S. Kim, C. R. Lee, J. H. Im, K. B. Lee, T. A. Marchioro, S. J. Moon, R. Humphry-Baker, J. H. Yum, M. Grätzel and N. G. Park, Sci. Rep., 2012, 2, 591.

3 S. D. Stranks, G. E. Eperon, G. Grancini, C. Menelaou, M. J. P. Alcocer, T. Leijtens, L. M. Herz, A. M. Petrozza and H. J. Snaith, Science, 2013, 342, 341.

4 Best Research-Cell Efficiency Chart, NREL. https://www. nrel.gov/pv/cell-efficiency.html. (Accessed October 2019).

5 R. Wang, M. Mujahid, Y. Duan, Z.-K. Wang, J. Xue and Y. Yang, Adv. Funct. Mater., 2019, 1808843.

6 M. M. Elsenety, A. Kaltzoglou, M. Antoniadou, I. Koutselas, A. G. Kontos and P. Falaras, Polyhedron, 2018, 150, 83-91.

7 M. M. Elsenety, M. Antoniadou, A. Kaltzoglou, A. G. Kontos, A. I. Philippopoulos, C. A. Mitsopoulou and P. Falaras, Mater. Chem. Phys., 2020, 239, 122310.

8 M. M. Elsenety, M. Antoniadou, N. Balis, A. Kaltzoglou, L. Sygellou, A. Stergiou, N. Tagmatarchis and P. Falaras, ACS Appl. Energy Mater., 2020, 3, 2465.

9 J. Fan, Y. Ma, C. Zhang, C. Liu, W. Li, R. E. I. Schropp and Y. Mai, Adv. Energy Mater., 2018, 1703421.

10 S. Gharibzadeh, B. A. Nejand, M. Jakoby, T. Abzieher, D. Hauschild, S. Moghadamzadeh, J. A. Schwenzer, P. Brenner, R. Schmager, A. A. Haghighirad, L. Weinhardt, U. Lemmer, B. S. Richards, I. A. Howard and U. W. Paetzold, Adv. Energy Mater., 2019, 1803699.

11 K. T. Cho, S. Paek, G. Grancini, C. Roldán-Carmona, P. Gao, Y. Lee and M. K. Nazeeruddin, Energy Environ. Sci., 2017, 10, 621.

12 N. Balis, A. A. Zaky, D. Perganti, A. Kaltzoglou, L. Sygellou, F. Katsaros, T. Stergiopoulos, A. G. Kontos and P. Falaras, ACS Appl. Energy Mater., 2018, 1, 6161.

13 A. A. Said, J. Xie, Y. Wang, Z. Wang, Y. Zhou, K. Zhao, W.-B. Gao, T. Michinobu and Q. Zhang, Small, 2019, 15, 1803339.

14 A. A. Said, J. Xie and Q. Zhang, Small, 2019, 15, 1900854.
15 N. Wang, K. Zhao, T. Ding, W. Liu, A. S. Ahmed, Z. Wang, M. Tian, X. W. Sun and Q. Zhang, Adv. Energy Mater., 2017, 7, 1700522.

16 P.-Ya. Gu, N. Wang, C. Wang, Y. Zhou, G. Long, M. Tian, W. Chen, X. W. Sun, M. G. Kanatzidis and Q. Zhang, J. Mater. Chem. A, 2017, 5, 7339.

17 M. B. Faheem, B. Khan, C. Feng, M. U. Farooq, F. Raziq, Y. Xiao and Y. Li, ACS Energy Lett., 2020, 5, 290.

18 Y. Lin, L. Shen, J. Dai, Y. Deng, Y. Wu, Y. Bai, X. Zheng, J. Wang, Y. Fang, H. Wei, W. Ma, X. C. Zeng, X. Zhan and J. Huang, Adv. Mater., 2017, 1604545.

19 W.-J. Yin, T. Shi and Y. Yan, Appl. Phys. Lett., 2014, 104, 063903.

20 Z. Wu, S. R. Raga, E. J. Juarez-Perez, X. Yao, Y. Jiang, L. K. Ono, Z. Ning, H. Tian and Y. Qi, Adv. Mater., 2018, 3, 1703670.

21 W. Kim, J. B. Park, H. Kim, K. Kim, J. Park, S. Cho, H. Lee, Y. Pak and G. Y. Jung, J. Mater. Chem. A, 2019, 7, 20832.

22 X. Gong, L. Guan, H. Pan, Q. Sun, X. Zhao, H. Li, H. Pan, Y. Shen, Y. Shao, L. Sun, Z. Cui, L. Ding and M. Wang, Adv. Funct. Mater., 2018, 1804286.

23 X. Li, C.-C. Chen, M. Cai, X. Hua, F. Xie, X. Liu, J. Hua, Y.-T. Long, H. Tian and L. Han, Adv. Energy Mater., 2018, 1800715.

24 T. Wu, Y. Wang, X. Li, Y. Wu, X. Meng, D. Cui, X. Yang and L. Han, Adv. Energy Mater, 2019, 1803766.

25 X. Feng, R. Chen, Z.-A. Nan, X. Lv, R. Meng, J. Cao and Y. Tang, Adv. Sci., 2019, 1802040.

26 X. Zhao, C. Yao, T. Liu, J. C. Hamill Jr., G. Olivier, N. Ndjawa, G. Cheng, N. Yao, H. Meng and Y.-L. Loo, Adv. Mater., 2019, 1904494.

27 S. Fu, X. Li, L. Wan, Y. Wu, W. Zhang, Y. Wang, Q. Bao and J. Fang, Adv. Energy Mater., 2019, 1901852.

28 N. Li, F. Xu, Z. Qiu, J. Liua, X. Wan, X. Zhu, H. Yu, C. Li, Y. Liu and B. Cao, J. Power Sources, 2019, 426, 188.

29 Z. Wang, A. Pradhan, M. A. Kamarudin, M. Pandey, S. S. Pandey, P. Zhang, C. Ng, A. S. M. Tripathi, T. Ma and S. Hayase, ACS Appl. Mater. Interfaces, 2019, 11, 10012.

30 Y. Zhou, H. Zhong, J. Han, M. Tai, X. Yin, M. Zhang, Z. Wu and H. Lin, J. Mater. Chem. A, 2019, 7, 26334.

31 S. Zhang, Z. Hu, J. Zhang, X. Jia, J. Jiang, Y. Chen, B. Lin, H. Jiang, B. Fang, N. Yuan and J. Ding, J. Power Sources, 2019, 438, 226987.

32 J. Cao, C. Li, X. Lv, X. Feng, R. Meng, Y. Wu and Y. Tang, J. Am. Chem. Soc., 2018, 140(37), 11577.

33 M. E. M. Zayed, R. M. El-Shishtawy, S. A. Elroby, K. O. AlFooty and Z. M. Al-amshany, Chem. Cent. J., 2018, 12, 26.

34 S. Zhang, A. Islam, X. Yang, C. Qin, K. Zhang, Y. Numata, H. Chen and L. Han, J. Mater. Chem. A, 2013, 1, 4812.

35 M. M. Tavakoli, P. Yadav, D. Prochowicz, M. Sponseller, A. Osherov, V. Bulović and J. Kong, Adv. Energy Mater., 2019, 1803587.

36 J. Chang, H. Chen, G. Wang, B. Wang, X. Chena and H. Yuan, RSC Adv., 2019, 9, 7015.

37 L. Yang, U. B. Cappel, E. L. Unger, M. Karlsson, K. M. Karlsson, E. Gabrielsson, L. Sun, G. Boschloo, 
A. Hagfeldt and E. M. J. Johansson, Phys. Chem. Chem. Phys., 2012, 14, 779.

38 Y. Li, C. Sun, P. Song, F. Ma, N. Kungwan and M. Sun, Sci. Rep., 2018, 8, 10089.

39 Y. Wu and W. Zhu, Chem. Soc. Rev., 2013, 42, 2039.

40 M. M. Tavakoli, M. Saliba, P. Yadav, P. Holzhey, A. Hagfeldt, S. M. Zakeeruddin and M. Grätzel, Adv. Energy Mater., 2019, 9, 1802646.

41 W. S. Yang, J. H. Noh, N. J. Jeon, Y. C. Kim, S. Ryu, J. Seo and S. I. Seok, Science, 2015, 348, 1234.

42 N. J. Jeon, J. H. Noh, W. S. Yang, Y. C. Kim, S. Ryu, J. Seo and S. I. Seok, Nature, 2015, 517, 476.

43 W. Zhang, M. Saliba, D. T. Moore, S. K. Pathak, M. T. Hörantner, T. Stergiopoulos, S. D. Stranks, G. E. Eperon, J. A. Alexander-Webber, A. Abate, A. Sadhanala, S. Yao, Y. Chen, R. H. Friend, L. A. Estroff, U. Wiesner and H. J. Snaith, Nat. Commun., 2015, 6, 6142.

44 V. Dryza and E. J. Bieske, J. Photochem. Photobiol., A, 2015, 302, 35.

45 H. Dong, M. Yue, S. Pang, W. Zhu, D. Chen, H. Xi, Z. Lin, J. Chang, J. Zhang, Y. Hao and C. Zhang, Sol. RRL, 2019, 3, 1900291.

46 D. Bi, C. Yi, J. Luo, J.-D. Decoppet, F. Zhang, S. M. Zakeeruddin, X. Li, A. Hagfeldt and M. Gratzel, Nat. Energy, 2016, 1, 16142.

47 T. Niu, J. Lu, R. Munir, J. Li, D. Barrit, X. Zhang, H. Hu, Z. Yang, A. Amassian, K. Zhao and S. F. Liu, Adv. Mater., 2018, 30, 1706576.
48 J.-H. Yum, D. P. Hagberg, S.-J. Moon, K. M. Karlsson, T. Marinado, L. Sun, A. Hagfeldt, M. K. Nazeeruddin and M. Grätzel, Angew. Chem., Int. Ed., 2009, 48, 1576.

49 D. P. Hagberg, X. Jiang, E. Gabrielsson, M. Linder, T. Marinado, T. Brinck, A. Hagfeldtbd and L. Sun, J. Mater. Chem., 2009, 19, 7232.

50 A. Peddapuram, H. Cheema, R. E. Adams, R. H. Schmehl and J. H. Delcamp, J. Phys. Chem. C, 2017, 121, 8770.

51 D. P. Hagberg, X. Jiang, E. Gabrielsson, M. Linder, T. Marinado, T. Brinck, A. Hagfeldt and L. Sun, J. Mater. Chem., 2009, 19, 7232.

52 Y. Shao, Z. Xiao, C. Bi, Y. Yuan and J. Huang, Nat. Commun., 2014, 5, 5784.

53 J. S. Manser and P. V. Kamat, Nat. Photonics, 2014, 8, 737.

54 V. Adinolfi, M. Yuan, R. Comin, E. S. Thibau, D. Shi, M. I. Saidaminov, P. Kanjanaboos, D. Kopilovic, S. Hoogland, Z.-H. Lu, O. M. Bakr and E. H. Sargent, Adv. Mater., 2016, 28, 3406.

55 H. Tan, A. Jain, O. Voznyy, X. Lan, F. P. G. de Arquer, J. Z. Fan, R. Quintero-Bermudez, M. Yuan, B. Zhang, Y. Zhao, F. Fan, P. Li, L. N. Quan, Y. Zhao, Z.-H. Lu, Z. Yang, S. Hoogland and E. H. Sargent, Science, 2016, 355, 722.

56 J. H. Heo, M. S. You, M. H. Chang, W. Yin, T. K. Ahn, S.-J. Lee, S.-J. Sung, D. H. Kim and S. H. Im, Nano Energy, 2015, 15, 530.

57 D. Yang, R. Yang, X. Ren, X. Zhu, Z. Yang, C. Li and S. F. Liu, Adv. Mater., 2016, 28, 5206.

58 Q. Jiang, Y. Zhao, X. Zhang, X. Yang, Y. Chen, Z. Chu, Q. Ye, X. Li, Z. Yin and J. You, Nat. Photonics, 2019, 13, 460. 